\title{
POST CERVICAL CONIZATION IN CERVICAL CARCINOMA
}

\author{
S. Alessandria, J. Lange, G. Torres, G. Devoto, L. Diaz, S. Tatti, A. Bermudez. \\ GYNECOLOGIC ONCOLOGY UNIT. BUENOS AIRES UNIVERSITY HOSPITAL. BUENOS AIRES, ARGENTINA.
}

\section{OBJECTIVE}

To determine the presence of residual disease in the radical surgery specimen, in patients with a diagnosis of cervical carcinoma stage IA1-IB1 after cervical conization.

\section{METHODS}

Retrospective study. We included 21 patients with cervical carcinoma stage IA1-IB1 treated in our Section between June 2005 and December 2018. All were submitted to diagnostic cervical conization followed by radical oncological surgery.Different variables have been analyzed to establish their relationship with the presence of residual disease (RD) in the final surgical specimen.

\section{RESULTS}

The average age of the patients was 34 years. There were 5 patients with stage FIGO IA1, 2 with stage IA2 and 15 with stage IB1.The margins of the cones were negative in 7 cases (36.4\%). In 14 (63.6\%) cases the margins were compromised; $4(28,6 \%)$ went for high-grade intraepithelial lesion, and $10(71,4 \%)$ for invasive carcinoma. The result of the pathological anatomies of the oncological surgeries after the cone showed the presence of carcinoma in 7 surgical pieces (31.8\%) (5 Type C Radical Hysterectomy $71,4 \%, 1$ trachelectomy 14,3\% and 1 Pelvic Lymphadenectomy 14,3\%), HSIL in 1 hysterectomy (4,5\%), and absence of injury in 15 cases (68,1\%) (10 Type C Radical Hysterectomy 73,3\%, 1 hysterectomies 6,6\% and 3 trachelectomy $20 \%)$.Age older than 34 years, the postmenopausal state, the presence of symptoms, the margins of the cone compromised by invasive injury, and stage IB were associated with a higher incidence of residual lesion in the post surgical radical surgical specimen.

\begin{tabular}{|l|c|c|c|c|c|c|}
\hline YEAR & AGE & STAGE & MARGINS & SURGERY & RD \\
\hline 2014 & 31 & IB1 & HSIL & RTQ PL MIS & Negative \\
\hline 2014 & 71 & IB1 & Inv Carcinoma & RTH Type C & Negative \\
\hline 2014 & 34 & IB1 & Inv Carcinoma & RTH Type C MIS & Negative \\
\hline 2013 & 33 & IA2 & Negative & RTH Type C MIS & Negative \\
\hline 2013 & 32 & IB1 & Negative & RTH Type C & Negative \\
\hline 2012 & 31 & IB1 & Negative & RTQ PL & Negative \\
\hline 2012 & 30 & IB1 & Inv Carcinoma & RTH Type C & Positive \\
\hline 2012 & 31 & IA1 & Negative & RTQ PL & Positive \\
\hline 2011 & 32 & IB1 & Negative & RTH Type C & Positive \\
\hline 2009 & 53 & IB1 & Inv Carcinoma & RTH Type C & Negative \\
\hline 2009 & 56 & IB1 & Inv Carcinoma & RTH Type C & Positive \\
\hline 2008 & 40 & IA1 & HSIL & Hysterectomy & Negative \\
\hline 2008 & 47 & IA1 & Negative & Hysterectomy & Negative \\
\hline 2007 & 45 & IA1 & Negative & Hysterectomy & Negative \\
\hline 2007 & 29 & IB1 & Inv Carcinoma & RTH Type C & Positive \\
\hline 2007 & 34 & IA1 & HSIL & RTH Type C & Positive \\
\hline 2006 & 28 & IB1 & Inv Carcinoma & RTH Type C & Negative \\
\hline 2005 & 38 & IB1 & HSIL & RTH Type C & Negative \\
\hline 2005 & 37 & IB1 & Inv Carcinoma & RTH Type C & Positive \\
\hline 2016 & 34 & IB1 & Inv Carcinoma & RTQ PL MIS & Negative \\
\hline 2018 & 28 & IA2 & Inv Carcinoma & RTQ PL & Negative \\
\hline 2018 & 51 & IB1 & Inv Carcinoma & RTH Type C & Negative \\
\hline & & & & & &
\end{tabular}

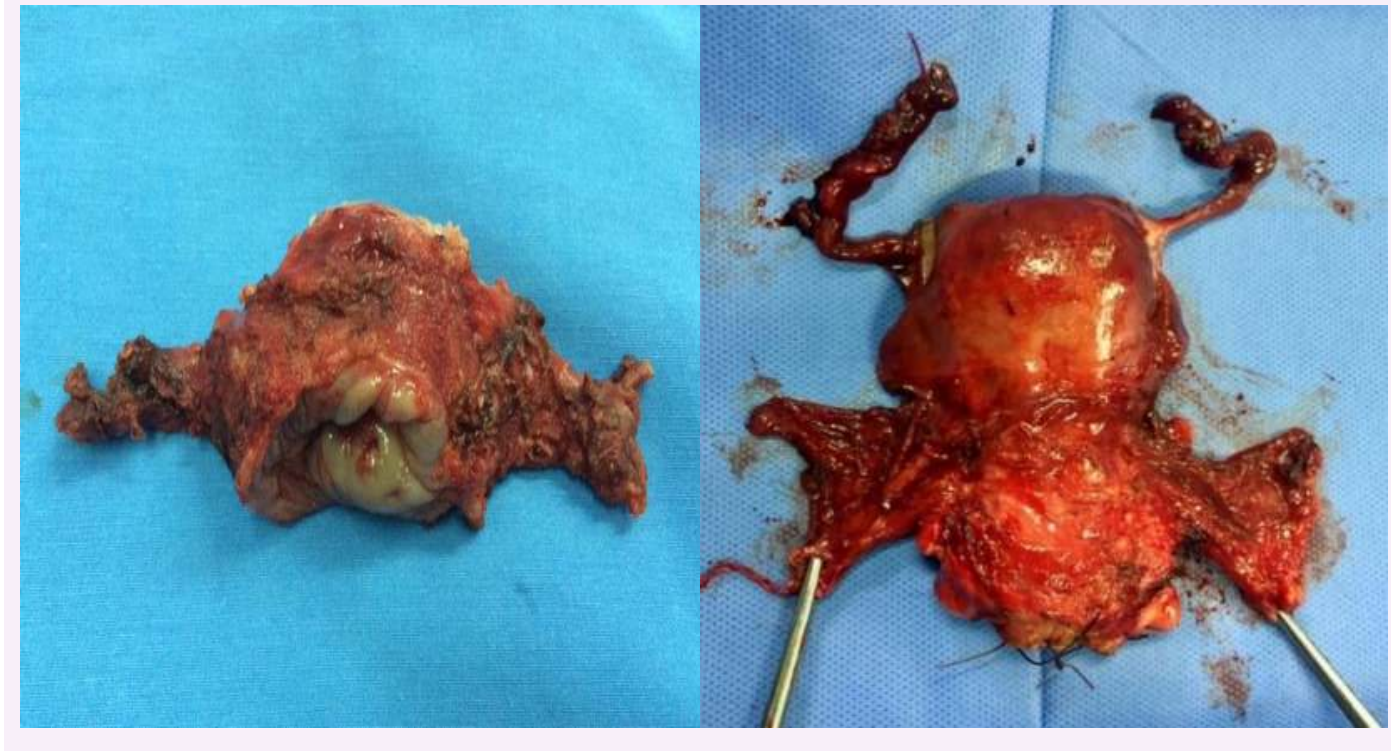

\section{CONCLUSION}

The characteristics of the patients, such as age and hormonal status, as well as margins of the conization piece and the histological type of the tumor are factors to be considered in the prediction of residual tumor postconization. 